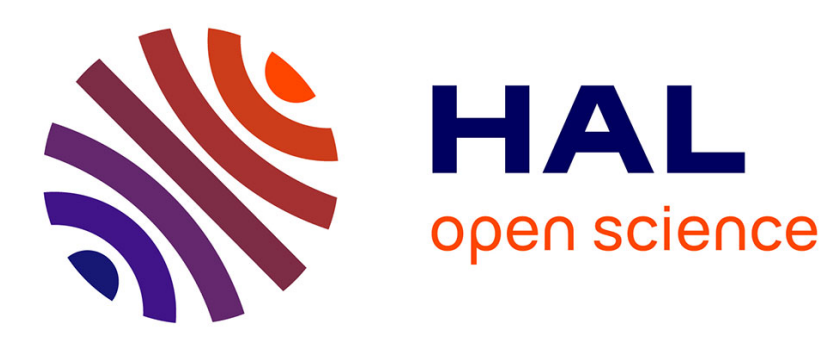

\title{
The CYP2C8 inhibitor gemfibrozil does not affect the pharmacokinetics of zafirlukast
}

\author{
Tiina Karonen, Pertti J. Neuvonen, Janne T. Backman
}

\section{To cite this version:}

Tiina Karonen, Pertti J. Neuvonen, Janne T. Backman. The CYP2C8 inhibitor gemfibrozil does not affect the pharmacokinetics of zafirlukast. European Journal of Clinical Pharmacology, 2010, 67 (2), pp.151-155. 10.1007/s00228-010-0908-0 . hal-00630277

\section{HAL Id: hal-00630277 \\ https://hal.science/hal-00630277}

Submitted on 8 Oct 2011

HAL is a multi-disciplinary open access archive for the deposit and dissemination of scientific research documents, whether they are published or not. The documents may come from teaching and research institutions in France or abroad, or from public or private research centers.
L'archive ouverte pluridisciplinaire HAL, est destinée au dépôt et à la diffusion de documents scientifiques de niveau recherche, publiés ou non, émanant des établissements d'enseignement et de recherche français ou étrangers, des laboratoires publics ou privés. 
The CYP2C8 inhibitor gemfibrozil does not affect the pharmacokinetics of zafirlukast

Tiina Karonen, Pertti J. Neuvonen and Janne T. Backman

Department of Clinical Pharmacology, University of Helsinki and Helsinki University Central Hospital, Helsinki, Finland

Correspondence and requests for reprints:

Janne T. Backman, MD

Department of Clinical Pharmacology, Helsinki University Central Hospital,

P.O. Box 705, FI-00029 HUS, Finland

Tel.: +358947173914

Fax: +358947174039

Email: janne.backman@hus.fi

A revised manuscript (EJCP-2010-0298R) including 11 pages, 1 figure and 1 table to be considered for publication in European Journal of Clinical Pharmacology 
Abstract Purpose: Gemfibrozil, a strong inhibitor of cytochrome P450 (CYP) 2C8 in vivo, was recently found to markedly increase the plasma concentrations of montelukast in humans. Like montelukast, zafirlukast is a substrate of CYP2C9 and CYP3A4 and a potent inhibitor of CYP2C8 in vitro. To investigate the contribution of CYP2C8 to the metabolism of zafirlukast in vivo, we studied the effect of gemfibrozil on the pharmacokinetics of zafirlukast. Methods: Ten healthy subjects took in a randomized cross-over study gemfibrozil $600 \mathrm{mg}$ or placebo twice daily for 5 days, and on day 3 , a single oral dose of $20 \mathrm{mg}$ zafirlukast. The plasma concentrations of zafirlukast were measured for 72 hours postdose. Results: The mean total area under the plasma concentration-time curve of zafirlukast during the gemfibrozil phase was $102 \%$ (geometric mean ratio; 95\% confidence interval $89-116 \%$ ) of that during the placebo phase. Furthermore, there were no statistically significant differences in the peak plasma concentration, time of peak concentration or elimination half-life of zafirlukast between the phases. Conclusions: Gemfibrozil has no effect on the pharmacokinetics of zafirlukast, indicating that CYP2C8 does not play a significant role in the elimination of zafirlukast.

Keywords gemfibrozil, zafirlukast, CYP2C8, drug interaction, pharmacokinetics 


\section{Introduction}

Zafirlukast and montelukast are cysteinyl leukotriene receptor antagonists used in the treatment of asthma [1-3]. The strong cytochrome P450 (CYP) 2C8 inhibitor gemfibrozil was recently shown to increase the area under the plasma concentration-time curve (AUC) of montelukast about 5-fold, markedly reducing the formation of its main metabolites [4]. These findings indicate that CYP2C8 plays a major role in the metabolism of montelukast, and diverge from the product information of Singulair ${ }^{\circledR}$, which gives CYP2A6, 2C9 and 3A4 as the enzymes involved in montelukast metabolism. However, the role of CYP2C8 in the metabolism of the structurally related leukotriene receptor antagonist zafirlukast is not known.

The absolute oral bioavailability of zafirlukast is unknown, but food reduces its absorption by $30-60 \%$ [5]. The peak plasma concentrations of zafirlukast are observed at about 3 hours after a single oral dose, and the plasma concentrations decline in a biphasic manner, with a terminal elimination half-life of about 10 hours $[5,6]$. Zafirlukast is highly bound to plasma proteins (99.799.9\%) and is extensively metabolised [5, 7]. According to preclinical in vitro studies, at least CYP2C9 and CYP3A4 can contribute to its hepatic microsomal metabolism [7-9]. Like montelukast, also zafirlukast is a CYP2C8 inhibitor in vitro, with an $\mathrm{IC}_{50}$ value of $0.6 \mu \mathrm{M}$ [10]. This is at least an order of magnitude lower than its $\mathrm{IC}_{50}$ value for $\mathrm{CYP} 2 \mathrm{C} 9$ or any other CYP isoform, consistent with a relatively selective inhibitory effect on CYP2C8 [10-13]. In vivo, however, neither montelukast nor zafirlukast affected the pharmacokinetics of the CYP2C8 substrate pioglitazone [14], indicating that despite their high affinity for CYP2C8, their free concentrations in vivo are not sufficient to cause inhibition of CYP2C8.

The major metabolite of gemfibrozil, gemfibrozil 1-O- $\beta$ glucuronide, is a potent and selective mechanism-based inhibitor of CYP2C8, which explains the strong and long-lasting CYP2C8 inhibitory effect of gemfibrozil in vivo [15-19]. In addition to increasing the concentrations of 
montelukast, gemfibrozil has increased the concentrations of several CYP2C8 substrates, e.g. the AUC of repaglinide 8-fold, that of cerivastatin 6-fold and that of pioglitazone 3-fold [20-23]. Gemfibrozil itself is also a relatively potent inhibitor of CYP2C9 in vitro, while its inhibitory effects on other CYP enzymes are weaker $[24,25]$. In vivo, however, it has not inhibited the CYP2C9-mediated metabolism of warfarin [26], and is therefore unlikely to have any significant inhibitory effects on CYP enzymes other than CYP2C8.

In this study, we investigated the possible effects of gemfibrozil on the pharmacokinetics of zafirlukast in healthy subjects, in order to find out whether CYP2C8 is involved in the metabolism of zafirlukast in humans, similarly as it was recently found to participate in the metabolism of montelukast. 


\section{Methods}

Subjects

Ten healthy volunteers ( 7 men, 3 women; age 20-27 years; weight $57-93 \mathrm{~kg}$ ) participated in the study after each gave a written informed consent and were ascertained to be healthy by medical history, clinical examination, and routine laboratory tests. None received continuous medication or used hormonal contraception or was a tobacco smoker. The study protocol was approved by the Coordinating Ethics Committee of the Helsinki and Uusimaa Hospital District and by the Finnish Medicines Agency.

Study design

A randomized, placebo-controlled, 2-phase crossover study with a washout period of 4 weeks between the phases was carried out. Each subject took either $600 \mathrm{mg}$ gemfibrozil (Lopid $600 \mathrm{mg}$ tablets, Gödecke, Freiburg, Germany), or unmatched placebo (University Pharmacy Placebo-tablets, University Pharmacy, Helsinki, Finland) twice daily at 0900 and 2100 hours for 5 days. On day 3, the morning dose of these medications was taken at 0800 hours, and $1 \mathrm{~h}$ later, a single dose of $20 \mathrm{mg}$ zafirlukast (Accolate $20 \mathrm{mg}$, Astra Zeneca UK Ltd., Macclesfield, UK) was administered orally with $150 \mathrm{ml}$ water. The subjects had fasted for 9 hours before zafirlukast intake and received a standardised meal $3 \mathrm{~h}$ and standardised light meals $7 \mathrm{~h}$ and $11 \mathrm{~h}$ after zafirlukast intake.

Blood sampling and determination of plasma drug concentrations

On days of zafirlukast administration, timed blood samples $(5$ or $10 \mathrm{ml})$ were drawn from a cannulated forearm vein before and $0.5,1,2,3,4,5,7,9,12,24,48$ and $72 \mathrm{~h}$ after administration of zafirlukast. 
Blood samples were collected into tubes containing ethylenediaminetetraacetic acid (EDTA). Plasma was separated immediately and stored at $-70^{\circ} \mathrm{C}$ until analysis.

Plasma samples (0.5 ml) were spiked with internal standard (IS; valdecoxib), and zafirlukast concentrations were measured by use of SCIEX API 2000 liquid chromatography-tandem mass spectrometry system (Sciex Division of MDS Inc, Toronto, ON, Canada) after extraction from plasma with ethyl acetate, as described earlier [27]. Chromatography was performed on a Symmetry C8 reversed phase column (2.1x150 mm; Waters Corporation, Milford Mass, USA) using gradient elution, as described [27]. The limit of quantification for zafirlukast was $0.5 \mathrm{ng} / \mathrm{ml}$. The between-day coefficient of variation (CV) for zafirlukast was $5.1 \%$ at $3.5 \mathrm{ng} / \mathrm{ml}, 11.1 \%$ at $35 \mathrm{ng} / \mathrm{ml}$ and $6.2 \%$ at $350 \mathrm{ng} / \mathrm{ml}$. Gemfibrozil and its glucuronide did not interfere with the assay.

The plasma concentrations of gemfibrozil and gemfibrozil 1- $O-\beta$ glucuronide in samples taken before and at 1, 3, 5, 9 and 12 hours after zafirlukast administration were determined by use of Applied Biosystems API 2000 Q Trap liquid chromatography-tandem mass spectrometry system (Sciex Division of MDS) as described before [19]. The limits of quantification for gemfibrozil and gemfibrozil $1-O-\beta$ glucuronide were $0.0025 \mu \mathrm{g} / \mathrm{ml}$ and the between-day $\mathrm{CVs}$ were $3.1-4.6 \%$ and $2.8-8.0 \%$ at relevant concentrations, respectively.

Pharmacokinetics

The pharmacokinetics of zafirlukast were characterised by peak plasma concentration $\left(\mathrm{C}_{\max }\right)$, time of peak plasma concentration $\left(t_{\max }\right)$, elimination half-life $\left(t_{1 / 2}\right)$, and AUC from 0 to 72 hours or infinity $\left(\mathrm{AUC}_{0-72,0-\infty}\right.$ ). The $\mathrm{C}_{\max }$ and $\mathrm{t}_{\max }$ values were taken directly from the original data. The terminal $\log$ linear part of each plasma concentration-time curve was identified visually, and the elimination rate constant $\left(\mathrm{k}_{\mathrm{e}}\right)$ was determined by linear regression analysis of the log-linear part of the concentrationtime curve. The $t_{1 / 2}$ was calculated by the equation $t_{1 / 2}=\ln 2 / k_{e}$. The AUC values were calculated by the 
linear trapezoidal rule for the rising phase and the log-linear trapezoidal rule for the descending phase, with extrapolation to infinity by division of the last measured concentration by $\mathrm{k}_{\mathrm{e}}$. The pharmacokinetics of gemfibrozil and gemfibrozil 1- $O-\beta$ glucuronide were characterised by peak plasma concentration $\left(\mathrm{C}_{\max }\right)$, time of peak plasma concentration $\left(\mathrm{t}_{\max }\right)$, and $\mathrm{AUC}$ from 0 to 13 hours after the morning dose of gemfibrozil on day $3\left(\mathrm{AUC}_{0-13}\right)$. The pharmacokinetic calculations were performed with MK-Model, version 5.0 (Biosoft, Cambridge, UK).

Statistical analysis

The pharmacokinetic variables between the two phases were compared with the paired t-test, or, in the case of $t_{\max }$, with the Wilcoxon signed-rank test. Logarithmic transformation of $\mathrm{C}_{\max }$ and AUC values was performed before statistical analysis, and $95 \%$ confidence intervals were calculated for the geometric mean ratios of these variables. The level of statistical significance was $P<0.05$. The analysis was performed with SPSS for Windows version 17.0 (SPSS Inc, Chicago, IL, USA). 


\section{Results}

Zafirlukast pharmacokinetics

Gemfibrozil $600 \mathrm{mg}$ twice daily had no significant effects on any of the pharmacokinetic variables of zafirlukast (Fig. 1, Table 1). The mean $\mathrm{AUC}_{(0-\infty)}$ of zafirlukast in the gemfibrozil phase, expressed as the geometric mean ratio, was $102 \%$ (range $72-137 \%, 95 \%$ confidence interval $89-116 \%, P=0.79$ ) of the control (placebo values). The mean $\left(\mathrm{C}_{\max }\right)$ of zafirlukast was $102 \%$ (range $65-134 \%, 95 \%$ confidence interval $87-120 \%, P=0.72$ ), and its mean elimination half-life $\left(\mathrm{t}_{1 / 2}\right)$ was $104 \%$ (range $85-131 \%$, $95 \%$ confidence interval $91-117 \%, P=0.50$ ) of the control. The $\mathrm{t}_{\max }$ of zafrlukast was not changed significantly by gemfibrozil.

Gemfibrozil and gemfibrozil 1-O-glucuronide

During the gemfibrozil phase on day 3 (i.e. when zafirlukast was administered), the mean \pm standard deviation (SD) $\mathrm{C}_{\max }$ of gemfibrozil was $23.4 \pm 6.9 \mu \mathrm{g} / \mathrm{ml}$ and its $\mathrm{AUC}_{0-13}$ was $98.9 \pm 42.2 \mu \mathrm{g} \mathrm{h} / \mathrm{ml}$ (Fig. 1). The mean $\mathrm{C}_{\max }$ of gemfibrozil $1-O-\beta$ glucuronide was $18.8 \pm 4.1 \mu \mathrm{g} / \mathrm{ml}$ and its $\mathrm{AUC}_{0-13}$ was $111.3 \pm$ $38.4 \mu \mathrm{g} \mathrm{h} / \mathrm{ml}$. The mean \pm SD predose morning concentrations of gemfibrozil and gemfibrozil 1-O- $\beta$ glucuronide were $1.8 \pm 1.7$ and $2.1 \pm 1.9 \mu \mathrm{g} / \mathrm{ml}$ on day $3,1.6 \pm 0.9$ and $2.2 \pm 1.5 \mu \mathrm{g} / \mathrm{ml}$ on day $4,1.2 \pm$ 0.6 and $1.7 \pm 1.0 \mu \mathrm{g} / \mathrm{ml}$ on day 5 and $1.5 \pm 0.6$ and $2.0 \pm 1.1 \mu \mathrm{g} / \mathrm{ml}$ on day 6 , respectively. The individual concentrations were consistent with good compliance by all subjects. 


\section{Discussion}

Zafirlukast has been shown to be a potent and relatively selective inhibitor of CYP2C8 in vitro, yet having no inhibitory effect on the metabolism of the CYP2C8 substrate pioglitazone in vivo [10, 12, 14]. In this and other regards zafirlukast is very similar to montelukast, whose concentrations are markedly increased by gemfibrozil [4]. This led us to investigate the effect of gemfibrozil on the pharmacokinetics of zafirlukast in healthy subjects, in order to compare the interaction susceptibility of zafirlukast to that of montelukast and to evaluate the role of CYP2C8 in the metabolism of zafirlukast in humans.

In the present study, which had a similar design compared with our previous gemfibrozilmontelukast study [4], the usual therapeutic dose of gemfibrozil (600 mg twice daily) did not affect the pharmacokinetic variables of zafirlukast in humans. The AUC, $\mathrm{C}_{\max }$, and $\mathrm{t}_{1 / 2}$ of zafirlukast remained practically unchanged compared to placebo, as demonstrated by the narrow 95\% CIs of their gemfibrozil/placebo geometric mean ratios. Based on individual plasma concentrations of gemfibrozil, the compliance in taking the gemfibrozil doses was excellent. Also, as the strong CYP2C8 inhibitory effect of gemfibrozil persists even after its concentrations have declined to less than $1 \%$ of its maximum concentration [19], the lack of interaction observed in the present study cannot be explained by the decline in plasma concentrations of gemfibrozil and gemfibrozil 1-O-glucuronide between gemfibrozil doses. Accordingly, our findings demonstrate with confidence that CYP2C8 does not contribute significantly to the elimination of zafirlukast in humans.

According to preclinical in vitro studies, which included evaluation of most major CYP enzymes (excluding CYP2C8), CYP2C9 and CYP3A4 are involved in the metabolism of zafirlukast in vitro [9]. In asthma patients, the CYP3A4 inhibitor erythromycin did not increase the concentrations of zafirlukast [7]. Thus, the contribution of CYP3A4 to the total metabolism of zafirlukast seems to very small in vivo. Furthermore, as the present findings indicate lack of contribution by CYP2C8, CYP2C9 
may be the major enzyme involved in the metabolism of zafirlukast in vivo. However, further studies are needed to resolve this question.

Like montelukast, zafirlukast has a high molecular weight (575.7, vs 608.2 for montelukast), its primary metabolic routes involve hydroxylation at multiple sites, and both CYP2C9 and CYP3A4 can catalyse its hydroxylations in vitro $[8,9]$. Furthermore, like montelukast, zafirlukast is a potent competitive inhibitor of CYP2C8 in vitro, with an $\mathrm{IC}_{50}$ value of $0.4 \mu \mathrm{M}$ [10], but due to extensive protein binding and very low unbound plasma concentrations (peak $<10 \mathrm{nM}$ ) it has no inhibitory effects on CYP2C8 in vivo [14]. In addition, the in vitro affinity of zafirlukast towards CYP2C8 is much higher than that towards CYP2C9 and CYP3A4 ( IC $_{50} 7.0 \mu \mathrm{M}$ and $20.9 \mu \mathrm{M}$, respectively) or other CYP forms [11]. Yet, the present findings indicate that montelukast and zafirlukast differ from each other with respect to the contribution of CYP2C8 to their metabolism. A possible explanation for this finding is that despite the high affinity of zafirlukast for $\mathrm{CYP} 2 \mathrm{C} 8$, the capacity (and intrinsic clearance) of CYP2C8 to metabolise zafirlukast is much lower than its capacity to metabolise montelukast.

The clinical implication of the present findings is that although montelukast concentrations are increased several fold by the strong CYP2C8 inhibitor gemfibrozil, the pharmacokinetics of zafirlukast are not affected by gemfibrozil. Thus, these structurally related cysteinyl leukotriene receptor antagonists clearly differ in the susceptibility to interact with gemfibrozil and probably also with other inhibitors of CYP2C8. Although both montelukast and zafirlukast are relatively safe drugs and the clinical significance of the gemfibrozil-montelukast interaction is probably limited, zafirlukast can be a preferable choice for patients requiring a leukotriene receptor antagonist, when using concomitantly gemfibrozil or another therapeutic drug inhibiting CYP2C8.

In conclusion, normal therapeutic doses of the fibric acid derivative gemfibrozil have no effect on the pharmacokinetics of zafirlukast in humans. These findings indicate that CYP2C8 does not 
contribute significantly to the metabolic elimination of zafirlukast in vivo. Moreover, unlike montelukast, zafirlukast is not susceptible to interactions involving the CYP2C8 enzyme, which makes it a preferable choice, compared to montelukast, in patients taking concomitantly CYP2C8 inhibiting drugs like gemfibrozil.

Acknowledgments We would like to thank Mrs Eija Mäkinen-Pulli, Mrs Lisbet Partanen and Mr Jouko Laitila for skilful technical assistance. This study was supported by grants from the Helsinki University Central Hospital Research Fund, and the Sigrid Jusélius Foundation, Finland. None of the authors has any financial or personal relationships that could be perceived as influencing the research described. The experiments comply with the current laws of Finland, and the study protocol was approved by the Coordinating Ethics Committee of the Helsinki and Uusimaa Hospital District and by the Finnish Medicines Agency. 


\section{References}

1 Calhoun WJ (1998) Summary of clinical trials with zafirlukast. Am J Respir Crit Care Med 157 (6 Pt 1): S238-246

2 Kelloway JS (1997) Zafirlukast: the first leukotriene-receptor antagonist approved for the treatment of asthma. Ann Pharmacother 31 (9): 1012-1021

3 Lipworth BJ (1999) Leukotriene-receptor antagonists. Lancet 353 (9146): 57-62

4 Karonen T, Filppula A, Laitila J, Niemi M, Neuvonen PJ, Backman JT (2010) Gemfibrozil markedly increases the plasma concentrations of montelukast: a previously unrecognized role for CYP2C8 in the metabolism of montelukast. Clin Pharmacol Ther 88 (2): 223-230

$5 \quad$ Accolate Pharmacology Review(s) $<\leq$ http://www.accessdata.fda.gov/drugsatfda_docs/nda/99/20-547-

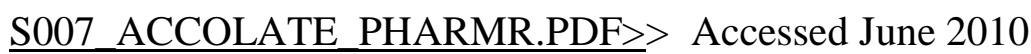

6 Dekhuijzen PN, Koopmans PP (2002) Pharmacokinetic profile of zafirlukast. Clin Pharmacokinet 41 (2): 105-114

$7 \quad$ Accolate label, AstraZeneca LP, 2009. < $\leq$ http://www.accessdata.fda.gov/drugsatfda_docs/label/2009/020547s027lbl.pdf > > Accessed May 2010.

8 Savidge RD, Bui KH, Birmingham BK, Morse JL, Spreen RC (1998) Metabolism and excretion of zafirlukast in dogs, rats, and mice. Drug Metab Dispos 26 (11): 1069-1076

9 Kassahun K, Skordos K, McIntosh I, Slaughter D, Doss GA, Baillie TA, Yost GS (2005) Zafirlukast metabolism by cytochrome $\mathrm{P} 4503 \mathrm{~A} 4$ produces an electrophilic alpha,betaunsaturated iminium species that results in the selective mechanism-based inactivation of the enzyme. Chem Res Toxicol 18 (9): 1427-1437

10 Walsky RL, Gaman EA, Obach RS (2005) Examination of 209 drugs for inhibition of cytochrome P450 2C8. J Clin Pharmacol 45 (1): 68-78

11 Shader RI, Granda BW, von Moltke LL, Giancarlo GM, Greenblatt DJ (1999) Inhibition of human cytochrome P450 isoforms in vitro by zafirlukast. Biopharm Drug Dispos 20 (8): 385388

12 Jaakkola T, Laitila J, Neuvonen PJ, Backman JT (2006) Pioglitazone is metabolised by CYP2C8 and CYP3A4 in vitro: potential for interactions with CYP2C8 inhibitors. Basic Clin Pharmacol Toxicol 99 (1): 44-51 
13 Walsky RL, Obach RS, Gaman EA, Gleeson JP, Proctor WR (2005) Selective inhibition of human cytochrome P4502C8 by montelukast. Drug Metab Dispos 33 (3): 413-418

14 Jaakkola T, Backman JT, Neuvonen M, Niemi M, Neuvonen PJ (2006) Montelukast and zafirlukast do not affect the pharmacokinetics of the CYP2C8 substrate pioglitazone. Eur J Clin Pharmacol 62 (7): 503-509

15 Shitara Y, Hirano M, Sato H, Sugiyama Y (2004) Gemfibrozil and its glucuronide inhibit the organic anion transporting polypeptide 2 (OATP2/OATP1B1:SLC21A6)-mediated hepatic uptake and CYP2C8-mediated metabolism of cerivastatin: analysis of the mechanism of the clinically relevant drug-drug interaction between cerivastatin and gemfibrozil. J Pharmacol Exp Ther 311 (1): 228-236

16 Ogilvie BW, Zhang D, Li W, Rodrigues AD, Gipson AE, Holsapple J, Toren P, Parkinson A (2006) Glucuronidation converts gemfibrozil to a potent, metabolism-dependent inhibitor of CYP2C8: implications for drug-drug interactions. Drug Metab Dispos 34 (1): 191-197

17 Baer BR, Delisle RK, Allen A (2009) Benzylic oxidation of gemfibrozil-1-O-beta-glucuronide by P450 2C8 leads to heme alkylation and irreversible inhibition. Chem Res Toxicol 22 (7): 1298-1309

18 Tornio A, Niemi M, Neuvonen M, Laitila J, Kalliokoski A, Neuvonen PJ, Backman JT (2008) The effect of gemfibrozil on repaglinide pharmacokinetics persists for at least $12 \mathrm{~h}$ after the dose: evidence for mechanism-based inhibition of CYP2C8 in vivo. Clin Pharmacol Ther 84 (3): 403-411

19 Backman JT, Honkalammi J, Neuvonen M, Kurkinen KJ, Tornio A, Niemi M, Neuvonen PJ (2009) CYP2C8 activity recovers within 96 hours after gemfibrozil dosing: estimation of CYP2C8 half-life using repaglinide as an in vivo probe. Drug Metab Dispos 37 (12): 2359-2366

20 Backman JT, Kyrklund C, Neuvonen M, Neuvonen PJ (2002) Gemfibrozil greatly increases plasma concentrations of cerivastatin. Clin Pharmacol Ther 72 (6): 685-691

21 Jaakkola T, Backman JT, Neuvonen M, Neuvonen PJ (2005) Effects of gemfibrozil, itraconazole, and their combination on the pharmacokinetics of pioglitazone. Clin Pharmacol Ther 77 (5): 404-414

22 Niemi M, Backman JT, Neuvonen M, Neuvonen PJ (2003) Effects of gemfibrozil, itraconazole, and their combination on the pharmacokinetics and pharmacodynamics of repaglinide: potentially hazardous interaction between gemfibrozil and repaglinide. Diabetologia 46 (3): $347-$ 351 
23 Deng LJ, Wang F, Li HD (2005) Effect of gemfibrozil on the pharmacokinetics of pioglitazone. Eur J Clin Pharmacol 61 (11): 831-836

24 Wen X, Wang JS, Backman JT, Kivisto KT, Neuvonen PJ (2001) Gemfibrozil is a potent inhibitor of human cytochrome P450 2C9. Drug Metab Dispos 29 (11): 1359-1361

25 Wang JS, Neuvonen M, Wen X, Backman JT, Neuvonen PJ (2002) Gemfibrozil inhibits CYP2C8-mediated cerivastatin metabolism in human liver microsomes. Drug Metab Dispos 30 (12): $1352-1356$

26 Lilja JJ, Backman JT, Neuvonen PJ (2005) Effect of gemfibrozil on the pharmacokinetics and pharmacodynamics of racemic warfarin in healthy subjects. Br J Clin Pharmacol 59 (4): 433-439

27 Bharathi DV, Naidu A, Jagadeesh B, Laxmi KN, Laxmi PR, Reddy PR, Mullangi R (2008) Development and validation of a sensitive LC-MS/MS method with electrospray ionization for quantitation of zafirlukast, a selective leukotriene antagonist in human plasma: application to a clinical pharmacokinetic study. Biomed Chromatogr 22 (6): 645-653 


\section{Figure 1}

Mean \pm SD plasma concentrations of zafirlukast (A) in 10 healthy volunteers after a single oral dose of $20 \mathrm{mg}$ zafirlukast on day 3 of a 5-day treatment with $600 \mathrm{mg}$ gemfibrozil twice daily, solid circles, or placebo, open circles. Inset depicts the same data on a semi-logarithmic scale. Mean \pm SD plasma concentrations of gemfibrozil, solid triangles, and gemfibrozil 1-O- $\beta$ glucuronide, open triangles, on day 3 (B). Time 0 refers to the administration of zafirlukast and time $-1 \mathrm{~h}$ refers to administration of the morning dose of gemfibrozil on day 3 . 
Table 1 Pharmacokinetic variables of zafirlukast in 10 healthy volunteers after a single oral dose of $20 \mathrm{mg}$ zafirlukast on day 3 of a 5-day treatment with $600 \mathrm{mg}$ gemfibrozil twice daily or placebo.

\begin{tabular}{|c|c|c|c|c|}
\hline Variable & $\begin{array}{l}\text { Placebo phase } \\
\text { (control) }\end{array}$ & Gemfibrozil phase & $\begin{array}{l}\text { Percentage of control } \\
(95 \% \text { CI })\end{array}$ & $P$-value \\
\hline $\begin{array}{l}\mathrm{C}_{\max }(\mathrm{ng} / \mathrm{ml}) \\
\quad \% \text { of control (range) }\end{array}$ & $\begin{array}{l}648 \pm 277 \\
100 \%\end{array}$ & $\begin{array}{l}664 \pm 267 \\
102 \%(65-134 \%)\end{array}$ & $102 \%(87-120 \%)$ & 0.8 \\
\hline $\mathrm{t}_{\max }(\mathrm{h})$ & $1.5(1-4)$ & $2(1-3)$ & & 0.3 \\
\hline $\begin{array}{l}\mathrm{t}_{1 / 2}(\mathrm{~h}) \\
\% \text { of control (range) }\end{array}$ & $\begin{array}{l}9.3 \pm 3.3 \\
100 \%\end{array}$ & $\begin{array}{l}9.7 \pm 3.3 \\
104 \%(85-131 \%)\end{array}$ & $104 \%(91-117 \%)$ & 0.5 \\
\hline $\begin{array}{l}\mathrm{AUC}_{0-\infty}(\mathrm{ng} \cdot \mathrm{h} / \mathrm{ml}) \\
\% \text { of control (range) }\end{array}$ & $\begin{array}{l}2087 \pm 1064 \\
100 \%\end{array}$ & $\begin{array}{l}2088 \pm 920 \\
100 \%(72-137 \%)\end{array}$ & $102 \%(89-116 \%)$ & 0.8 \\
\hline
\end{tabular}

Data are mean $\pm S D ; t_{\max }$ data are given as median with range. $C_{\max }$, observed peak plasma concentration; $t_{\max }$, time to reach $\mathrm{C}_{\max } ; \mathrm{t}_{1 / 2}$, elimination half-life; $\mathrm{AUC}_{0-\infty}$, area under the plasma concentration versus time curve. 